\begin{tabular}{|c|c|c|c|c|c|c|}
\hline \multirow{2}{*}{ 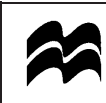 } & EC P O & 345 & \multirow{2}{*}{ B } & Dispatch: 8.1.09 & Journal: ECPO & CE: Blackwell \\
\hline & Journal Name & Manuscript No. & & Author Received: & No. of pages: 22 & PE: Chris/Thanuja \\
\hline
\end{tabular}

ECONOMICS \& POLITICS

DOI: $10.1111 / j .1468-0343.2009 .00345 . x$

Volume un

2009

No.

\title{
POLITICAL PREDATION AND ECONOMIC DEVELOPMENT
}

\author{
JEAn Paul AZAm, Robert BAtes, AND Bruno Biais*
}

\begin{abstract}
We analyze a game between citizens and governments, whose type (benevolent or predatory) is unknown to the public. Opportunistic governments mix between predation and restraint. As long as restraint is observed, political expectations improve, people enter the modern sector, and the economy grows. Once there is predation, the reputation of the government is ruined and the economy collapses. If citizens are unable to overthrow this government, the collapse is durable. Otherwise, a new government is drawn and the economy can rebound. Consistent with stylized facts, equilibrium political and economic histories are random, unstable, and exhibit long-term divergence.
\end{abstract}

\section{INTRODUCTION}

AS STRESSED by Rodrik (1999), "the notion that countries can be neatly separated into high-, medium- and low-growth groups over the longer term is an illusion ..." (p. 387). His statement comes in response to the empirical findings of Easterly et al. (1993): growth in 1960-1975, they find, was but weakly related to growth in 1975-1989. Countries had thus experienced dramatic changes in growth rates, while growth fundamentals had little changed. Following up on these findings, Pritchett (2000) confirms the importance of inflexions in growth paths, identifying particular periods of growth ("plateaus" or "plains") and episodes of rapid decline ("mountains"). Jerzmanowski (2006) too emphasizes such dynamics and captures them within a Markov switching model, where regime shifts cause sharp changes in the growth process. Increasingly scholars, such as Hausmann et al. (2006) and Rodrik (1999), explore the impact of political factors, such as wars or regime changes, to account for changes in growth rates.

This paper proposes a theoretical model that generates sharp changes in growth rates due to political factors. We focus on the evolution of private agents' expectations about how their government is likely to behave. Paraphrasing Weingast (1995), if the government is powerful enough to create property rights, it is also powerful enough to violate them. It is beliefs about how the government will employ its power that count.

To capture the manner in which economies enter and persist in various growth regimes, we develop a dynamic model in which citizens are not perfectly informed about the type of the government and update their beliefs

\footnotetext{
*Corresponding author: Bruno Biais, Toulouse School of Economics, Université de Toulouse, 21 Allées de Brienne, 31000 Toulouse, France. E-mail: biais@cict.fr
} 
based on past observations. We assume the government could be either benevolent or predatory. The latter type extracts rents by utilizing a wellknown range of instruments (e.g. Bates, 1981; Lal, 1983).

In developing our argument, we make use of a variant of the standard model of a two-sector economy (e.g. Lewis, 1954). Development results from the transfer of resources from a less productive sector, which we will call the informal or traditional sector, to a more productive, which we call the formal or modern. Citizens in the traditional sector are self-employed or work as household laborers, artisans, or farmers. In the modern sector, industrial or agricultural firms utilize new technologies and physical capital on a relatively large scale. ${ }^{1}$ They also rely on certification and information techniques, provided by financial intermediaries and accountants that enhance their ability to make use of sophisticated contracts (see Hicks, 1969). While modern firms are more productive, they are also more visible and vulnerable to exactions by politicians. In contrast, informal activities are less visible, and it is more costly and less rewarding for the government to expropriate them (De Soto, 1989).

At each period, citizens choose whether to operate in the informal or formal sector. Then the government, if opportunistic, decides whether or not to predate. Thus, the government's choice provides a signal of its type. ${ }^{2}$ While predation generates immediate benefits for the opportunistic government, restraint enhances political optimism, encouraging citizens to enter the formal sector. An opportunistic government, rationally anticipating the response of the citizens, trades off the immediate costs of restraint against the benefits of future predation. Its strategy takes the form of mixing between predation and restraint. The a priori distribution of the government's type and of its policy choices determine the citizens' assessment of political risk and thus the growth of the economy. ${ }^{3}$

As long as the government does not predate, political optimism increases; as resources flow to the modern sector, the economy expands. Citizens, however, rationally anticipate predatory governments to mimic the behavior of benevolent ones. They are not certain whether the history of restraint reveals the presence of a benevolent government or merely reflects the efforts of a predatory one to "fatten" the modern sector before engaging in predation. The resulting political risk lowers the growth rate. It also shapes the distribution of income. Because wages in the modern sector can be expropriated, they include a risk premium. Hence, there is a wedge between the compensation promised in the modern sector and that obtained in the

\footnotetext{
${ }^{1}$ Note, however, that our model does not explicitly rely on economies of scale, and thus differs from the class of two-sector models running from Murphy et al. (1989a, 1989b) to RosensteinRodan (1943).

${ }^{2}$ Our analysis is in line with the reputation models of Kreps and Wilson (1982) and Milgrom and Roberts (1982).

${ }^{3}$ Thus policy risk arises endogenously, reflecting the strategies of political and economic agents. This differs from exogenous random policy reversals or changes in the government (Alesina and Tabellini, 1989; Rodrik, 1991).
} 
traditional. The risk premium, which is decreasing in the political reputation of the government, lowers the profits of modern sector firms.

The equilibrium dynamics of the politico-economic system are characterized by a Markov chain. Both the extreme states - where the type of the current government is known - and the interior states - where the citizens are gradually learning about the government's type - have positive probability in the ergodic distribution. Thus, our theoretical model generates dynamics that are in line with recent empirical findings: persistent divergences arise (Maddison, 2001), collapse can follow sustained growth (Easterly et al., 1993; Pritchett, 2000), regime shifts follow a Markov process (Jerzmanowski, 2006), and political events can trigger these shifts (Rodrik, 1999; Hausmann et al., 2006). ${ }^{4}$

Our paper complements the institutionalist theories of development (see e.g. Acemoglu et al., 2001, 2002; Acemoglu and Johnson, 2004; Engerman and Sokoloff, 1997; North and Weingast, 1989; Root, 1989). In addition to institutions, we emphasize citizens' beliefs and heterogeneity in government types. Our approach is consistent with the empirical findings of Jones and Olken (2004) that leaders' identities matter for growth. It is also related to Besley (1997). But, in the latter, in contrast with our analysis, there are no informational asymmetries about the type of the government, nor does predation on the equilibrium path. Our analysis also complements previous analyses of asymmetric information about governments. Rodrik (1989) shows that good governments signal their types by implementing larger reforms than in the first best. Perotti (1995) shows how benevolent governments breed confidence by following gradual privatization policies. Phelan (2004) studies financial and monetary crises. ${ }^{5}$

The next section presents our model. Section 3 presents the politico-economic histories arising in equilibrium. Section 4 presents an extension of our model where even benevolent governments extract some resources from the private sector. Section 5 presents empirical implications of our theoretical analysis. Section 6 offers some concluding comments. Proofs are in Appendix A.

\section{THE MODEL}

\subsection{Citizens and Governments}

Consider a discrete time, infinite horizon model where time $t$ goes from 1 to infinity. The actors - each rational and risk neutral - include a unit mass continuum of private citizens and an agent that possesses the power to en-

\footnotetext{
${ }^{4}$ Our theoretical analysis also generates dynamics that are in line with the empirical findings of Glaeser et al. (2004). In our equilibrium as well as in their empirical results, poor countries get out of poverty when dictators follow good policies and along this process institutions improve.

${ }^{5}$ Our modeling framework differs from Phelan's in particular because, unlike us, he assumes that there are unobservable changes in government type, and because we study wages and inequality, while he does not.
} 
gage in predation. The potential predator can be the current government or another political player who might attempt to seize power and expropriate other people's wealth. For simplicity, we hereafter refer to the potential predator as the government. Before the game, nature selects the government's type. With probability $\pi_{0}$, the government is relatively benevolent. With the complementary probability $\left(1-\pi_{0}\right)$, it is opportunistic.

For simplicity we first assume that the benevolent government fully refrains from predation, while the opportunistic government must choose between full restraint and full predation. We later extend our analysis to consider a less stylized model. As does Besley (1997), we assume a benevolent government also extracts resources from the private sector and that an opportunistic government must choose between such limited extraction and predation. We show that our qualitative results still obtain in that setting.

\subsection{The Modern Sector and the Traditional Sector}

In line with Lewis (1954) and others (e.g. Harris and Todaro, 1970), we assume a two-sector economy. The traditional sector is less productive than the modern (which we also term the formal) sector of the economy. Because they benefit from access to superior technologies and better infrastructure, firms operating in the modern sector are more productive. Economic development occurs as resources move from the traditional sector to the modern.

Denote by $\beta_{t}$ the fraction of agents operating in the modern sector at time $t$, and by $1-\beta_{t}$ the fraction of agents operating in the traditional sector. For simplicity, we set output in the traditional sector to $1-\beta_{t}$, i.e. the marginal product in the traditional sector is constant and normalized to one. Output in the modern sector is $Y\left(\beta_{t}\right)$. The production function $Y($.$) is continuous,$ increasing, and concave. Again for simplicity, we consider only one input: labor. We assume the modern sector is more productive than the traditional sector, i.e. $Y^{\prime}(\beta) \geq 1, \forall \beta \in[0,1]$. Efficiency therefore requires that all the population work in the modern sector. To simplify the analysis we assume that $Y^{\prime}(1)=1$, which implies that, when all agents work in the modern sector, marginal productivity is equalized in the two sectors. As will be seen, this assumption also implies that, with positive levels of political risk, the optimal value of $\beta$ remains strictly lower than 1 .

In this context, the first-best allocation is the solution of $\operatorname{Max}_{\beta_{t} \in[0,1]} Y\left(\beta_{t}\right)+\left(1-\beta_{t}\right)$. Concavity of the production function implies that the second-order condition holds. Under our assumption that $Y^{\prime}(1)=1$, the optimum is pinned down by the first-order condition and $\beta=1$. When there is no risk of predation, the competitive equilibrium implements this allocation. Citizens working in the traditional sector obtain their marginal productivity equal to 1 . Those employed in the modern sector receive wage $w$. As long as $\beta<1$, equilibrium requires that workers be indifferent between taking a job in the modern sector and being self-employed in the traditional sector, implying 
that $w=1 .^{6}$ The modern sector firms are competitive and maximize profits $Y\left(\beta_{t}\right)-\beta_{t} w$ taking wages as given. This yields the first-best allocation.

\subsection{The Risk of Predation}

The greater efficiency of the formal sector comes at the cost of greater political risk. Whether because the firms are larger, less mobile, or more visible, an opportunistic government finds it not only more lucrative but also less costly to prey upon output from the formal sector. To capture this vulnerability in the simplest possible way, we initially assume that, when the government chooses to predate at time $t$, it endeavors to capture the output of the modern sector: $Y\left(\beta_{t}\right)$. If it is successful, the profits of private firms are entirely expropriated and wages in the modern sector are not paid. In contrast, we assume that output in the traditional sector is protected from political predation. Thus, the risk of political predation can deter citizens from leaving the safe traditional sector to enter the more productive modern sector.

At the beginning of each period, citizens make the initial move, choosing whether to work in the traditional or modern sector. The predatory agent then chooses whether to seize the output of the latter sector or to refrain from predation. His strategy is described by the probability that it refrains from predation at time $t$, denoted by $\mu_{t}$. If the opportunistic government never predates at time $t$, then $\mu_{t}=1$. If it always engages in predation, $\mu_{t}=0$. The intermediary case $\left(0<\mu_{t}<1\right)$ corresponds to a mixed strategy. Figure 1 portrays the sequence of play.

While citizens are initially uncertain about the government's type, they rationally update their prior expectations after observing its behavior. Because their actions play the role of a signal, predatory agents possess an incentive to pool with benevolent ones, initially refraining from predation so as to enhance their reputation and subsequently secure a larger gain.

\subsection{Political Instability}

The government's discount rate is $\delta_{G}<1$, which can also be interpreted as the probability that the government remains in power. In that interpretation, with probability $1-\delta_{G}$ there can be an exogenous political shock, such as an invasion or the death of the political leader and a new government takes over at time $t+1$, with initial reputation $\pi_{0}{ }^{7}$ As far as the mathematical analysis of the government policy is concerned, the two interpretations - one in terms of

\footnotetext{
${ }^{6}$ This indifference condition is sufficient but not necessary when $\beta=1$.

${ }^{7}$ Mozambique offers an example (see Jones and Olken, 2004). Its historical leader, Samora Machel, was a predatory autocrat. Consistent with our theory, under his leadership Mozambique had very low growth. In 1986, Samora Machel died, which can be interpreted as an exogenous shock. Joaquin Chissano became the new national leader, which can be interpreted as a new draw, as in our model. Consistent with our model, as this new leader refrained from predation, the growth rate rose.
} 


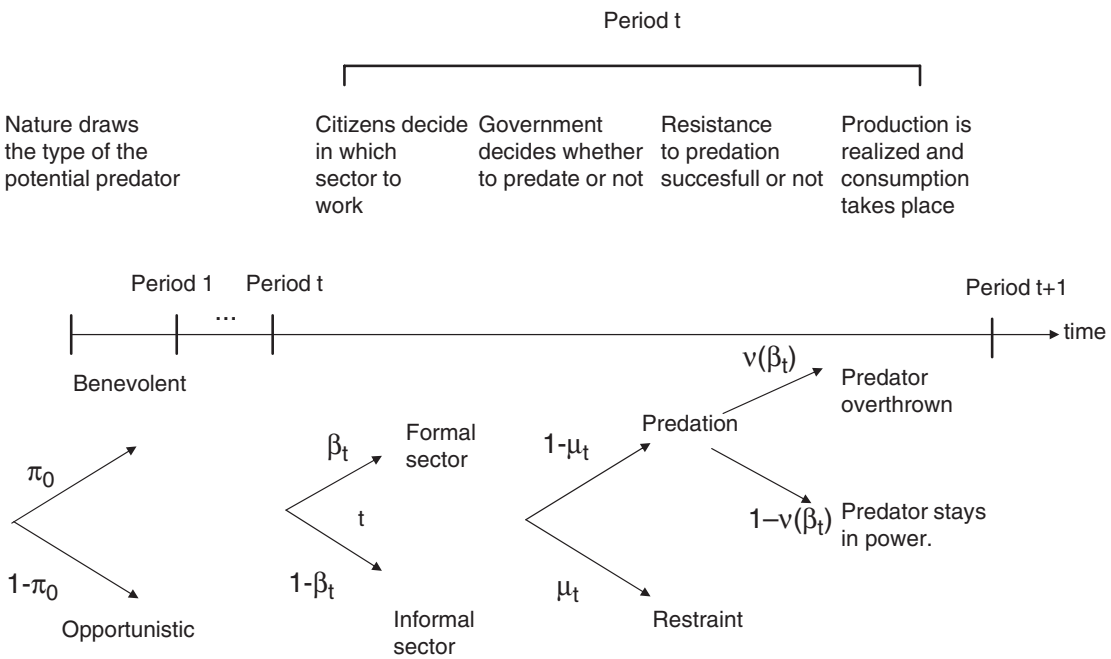

Figure 1. The Sequence of Play.

discount rate and the other in terms of exogenous political shocks are equivalent.

After predation, with probability $v$, the government is overthrown and a new government takes over, with initial reputation $\pi_{0}$. In that case the modern sector is not expropriated and wages are paid. In contrast, when the government successfully predates and stays in power, modern firms are expropriated and modern sector wages are not paid. To simplify the analysis, we assume $v<1 / Y^{\prime}(0)$, which implies that when citizens are sure that the government will predate they prefer not to enter the modern sector.

\section{EQUILIBRIUM HISTORIES}

The joint evolution of predation and entry in the formal sector arises as the equilibrium outcome of a dynamic game. At each point in time, $t$, the private sector and the government choose their optimal actions: $\beta_{t}$ and $\mu_{t}$. Denote by $\pi_{t-1}$ the updated probability that the government is non-predatory, given the sequence of moves from time 1 to time $t-1$.

The state variable is the reputation of the government, $\pi_{t-1}$, or equivalently the number of periods during which this government has shown restraint. Markov perfect equilibrium requires that each agent takes optimal actions, given its rational interpretation of past observations, summarized by $\pi_{t-1}$, and its rational anticipations about the optimal actions taken in the continuation subgames (see Maskin and Tirole, 2001). 


\subsection{The Dynamics of Political Risk}

Denote by $\lambda_{t}$ the probability that the government will show restraint at time $t$ given the information set of the agents in the economy:

$$
\lambda_{t}=\pi_{t-1}+\left(1-\pi_{t-1}\right) \mu_{t} .
$$

Applying Bayes' rule, the dynamics of $\pi_{t-1}$ as a function of $\mu_{t}$ and the sequence of moves is readily obtained, and is given in the next lemma.

Lemma 1. As soon as the government predates, $\pi_{t-1}$ goes to 0 . If the government has not predated at time $1, \ldots, t-1$, the probability that it is benevolent is

$$
\pi_{t-1}=\frac{\pi_{0}}{\pi_{0}+\left(1-\pi_{0}\right) \mu_{1} \ldots \mu_{t-1}} .
$$

Lemma 1 implies that, on the no-predation path, the probability that the government is benevolent increases, i.e. the reputation of the government improves over time. On the other hand, when the government predates, its reputation is permanently destroyed.

\subsection{Private Sector Choices}

Citizens who choose to operate in the traditional sector receive their marginal product, equal to 1 . Those who choose to operate in the modern sector at time $t$ receive their wage $w_{t}$ if the government does not predate or if, after attempting to predate, the government is overthrown. Equilibrium in the labor market implies that citizens be indifferent between self-employment in the informal sector and employment in the modern sector. Hence,

$$
w_{t}=\frac{1}{\lambda_{t}+\left(1-\lambda_{t}\right) v} .
$$

Taking the wage rate as given, the modern sector firms choose how many workers to hire to maximize expected profits:

$$
\max _{\beta_{t} \in[0,1]}\left(\lambda_{t}+\left(1-\lambda_{t}\right) v\right)\left(Y\left(\beta_{t}\right)-\beta_{t} w_{t}\right) .
$$

Substituting in the equilibrium wage, expected profits in the modern sector are $\left(\lambda_{t}+\left(1-\lambda_{t}\right) v\right) Y\left(\beta_{t}\right)-\beta_{t}$. The solution of this program is given in the next lemma.

Lemma 2. If $\lambda_{t}=1$, then all citizens operate in the modern sector. If $\lambda_{t}=0$, then all citizens operate in the traditional sector. For interior values of $\lambda_{t}$, the fraction of citizens employed in the traditional sector, $\beta_{t}$, is an increasing 
function of $\lambda_{t}$ denoted by $B($.$) :$

$$
\beta_{t}=B\left(\lambda_{t}\right)=Y^{\prime-1}\left(\frac{1}{\lambda_{t}+\left(1-\lambda_{t}\right) v}\right) .
$$

As the probability that there will be no predation $\left(\lambda_{t}\right)$ rises from 0 to 1 , the fraction of the population working in the formal sector $\left(B\left(\lambda_{t}\right)\right)$ increases from 0 to 1 . Since the modern sector is more productive than the traditional one, GDP per capita is increasing in $\lambda_{t}$, i.e. it is decreasing in political risk. Note also that the sensitivity of economic development $\left(\beta_{t}\right)$ to political risk $\left(\lambda_{t}\right)$ is lower when the ability of the people to resist full predation $(v)$ is large.

For interior values of, the fraction of the population operating in the formal sector is given by the first-order condition:

$$
Y^{\prime}\left(\beta_{t}\right)=w_{t}=\frac{1}{\lambda_{t}+\left(1-\lambda_{t}\right) v},
$$

which simply equates the marginal productivity of labor to wages in the modern sector. The greater the political risk, the greater the wages necessary to attract agents in the modern sector.

\subsection{The Program of an Opportunistic Government}

We now analyze the problem from the point of view of an opportunistic government. Once the government has predated, its reputation is ruined; citizens permanently exit the vulnerable modern sector and there is no further predatory gain. Denote by $J_{t}$ the value function of the opportunistic government if it has not predated until time $t$. The expected utility of the government when it engages in predation is the product of the probability that the government will stay in power and the output it can then expropriate. Denote this expected gain by $\varphi\left(\beta_{t}\right)$ :

$$
\varphi\left(\beta_{t}\right)=(1-v) Y\left(\beta_{t}\right) .
$$

Denote by $J_{t}$ the value function of the opportunistic government after $t$ periods of restraint. It is defined by the following Bellman equation:

$$
J_{t}=\max _{\mu_{t} \in[0,1]}\left\{\left(1-\mu_{t}\right) \varphi\left(\beta_{t}\right)+\mu_{t} \delta_{G} J_{t+1}\right\} .
$$

As long as the opportunistic government shows some restraint, i.e. as long as $\mu_{t}>0$, the first-order condition states that the government is indifferent between immediate predation and restraint. ${ }^{8}$ Thus, on the no-predation path, $J_{t}=\varphi\left(\beta_{t}\right)=\delta_{G} J_{t+1}$. This equality emphasizes the link between the value function of the government and the current level of development of the

\footnotetext{
${ }^{8} \mu_{t}=1$ never arises in equilibrium. Were citizens to expect $\mu_{t}=1$, then restraint at time $t$, while costly for the impatient government, would not improve its reputation.
} 
modern sector. Indeed, the latter determines how much the government can obtain if it predates immediately, thus anchoring its value function.

\subsection{Equilibrium}

From this infinite horizon game, a finite horizon emerges endogenously. Intuitively, as the number of periods without predation increases, the updated probability that the government is benevolent increases. This increased optimism generates an increase in the fraction of the population operating in the formal sector. The expansion of the modern economy, in turn, raises the attractiveness of predation for the opportunistic government. At some point the temptation grows so large that an opportunistic government can no longer resist. At this point, it predates.

To make this point more formally, first define $\beta^{*}$ as the level of development of the formal sector such that the opportunistic government is indifferent between predating now and waiting, for full development at the next period ${ }^{9}$ :

$$
\beta^{*}=Y^{-1}\left(\delta_{G} Y(1)\right)
$$

Second, define $\pi^{*}$ as the level of the probability that the government is benevolent, such that a fraction $\beta^{*}$ of the citizens is willing to enter the modern sector, even while anticipating that the government, if opportunistic, would predate for sure, i.e. $\beta^{*}=B\left(\pi^{*}\right)$. Since $B$ is increasing it is invertible. Hence, we can write $\pi^{*}$ as

$$
\pi^{*}=B^{-1}\left(\beta^{*}\right)
$$

The following proposition directly stems from these definitions.

Proposition 1. When $\pi_{t}$ reaches $\pi^{*}$, then the following is a Nash equilibrium of the continuation game: an opportunistic government always predates $\left(\mu_{t}=0\right)$ and a fraction $\beta^{*}$ of the citizens choose to enter the formal sector. If there is no predation at time $t$, then the economy reaches full development at the next period, i.e. $\beta_{t+s}=1, \forall s \geq 1$.

Denote by $T$ the endogenous horizon of our politico-economic game. After observing $T-1$ periods without predation, the probability that the government is benevolent reaches $\pi^{*}{ }^{10}$ Thus, at time $T$, by construction, the value function of the government is $J_{T}=\delta_{G} \varphi(1)$. Before time $T$, the government follows a mixed strategy and thus is indifferent between predation and

\footnotetext{
${ }^{9}$ Note that $\beta^{*}$ is strictly lower than 1 .

${ }^{10}$ Because we work in discrete time, we face an integer number problem: at time $T-1$, the conditional probability that the government is opportunistic is strictly below $\pi^{*}$, and at time $T$ it is (generically) strictly above. To avoid technicalities, we neglect the integer problem, and work as if at time $T$ the updated probability that the government is opportunistic just reached $\pi^{*}$.
} 
restraint. Hence, $J_{T-1}=\varphi\left(\beta_{T-1}\right)=\delta_{G}^{2} \varphi(1)$. Iterating, $J_{T-k}=\varphi\left(\beta_{T-k}\right)=$ $\delta_{G}^{k+1} \varphi(1)$. As noted in the following lemma, this expression pins down the value function of the opportunistic government and the fraction of the population operating in the modern sector on the no-predation path.

Lemma 3. On the no-predation path, $\forall t \leq T$, the opportunistic government value function is

$$
J_{t}=\delta_{G}^{T+1-t} \varphi(1),
$$

and the fraction of the population working in the modern sector is

$$
\beta_{t}=\varphi^{-1}\left(\delta_{G}^{T+1-t} \varphi(1)\right) .
$$

The mixed strategy indifference condition implies that the value function of the opportunistic government on the no-predation path is the present value of its payoff at the endogenous final date $T$, as stated in equation (4). This value function increases with time. The indifference condition also implies that the fraction of the population operating in the modern sector is $\varphi^{-1}\left(J_{t}\right)$. Since $\varphi($.$) is increasing between 0$ and $\beta^{*}, \beta_{t}$ also increases with time on the no-predation path.

Turning to the dynamics of political risk, equation (3) expresses the fraction of the population operating in the modern sector in a given period as a function of the probability that there will be no predation during that period. Since this function is increasing, it can be inverted, which yields $\lambda_{t}=B^{-1}\left(\beta_{t}\right)$. Substituting the equilibrium fraction of the population employed in the modern sector from equation (5), we obtain the following lemma:

Lemma 4. After $t-1$ periods without predation, the citizens evaluate the probability of no current predation as

$$
\lambda_{t}=B^{-1}\left(\varphi^{-1}\left(\delta_{G}^{T+1-t} \varphi(1)\right)\right)=B^{-1}\left(Y^{-1}\left(\delta_{G}^{T+1-t} Y(1)\right)\right),
$$

which is increasing in $t$.

Summarizing the above results, on the no-predation path the modern sector gradually increases in size. So too does per capita income and the ability of the civil society to resist expropriation. During this process, political risk decreases. Our theoretical analysis thus offers an equilibrium interpretation for the jointly endogenous evolution of the economy and the polity. But, even with successful development, in equilibrium, as long as $t<T+1$, predation can occur.

To complete the characterization of equilibrium strategies, we need to determine the strategy of the opportunistic government and the citizens' beliefs, i.e. the evolution of $\mu_{t}$ and $\pi_{t-1}$, on the no-predation path. This can be achieved by drawing upon the implications of Bayes rule for the dynamics 
of beliefs (Lemma 1), and combining the analysis of private sector choices (Lemma 2) with that of the government strategy (Lemmas 3 and 4).

Proposition 2. There exists an equilibrium whereby after a sufficiently long time without predation the updated probability that the government is benevolent reaches $\pi^{*}$. On the no-predation path, the equilibrium probability that the opportunistic government refrains from predation is

$$
\begin{aligned}
\mu_{t}= & \frac{\lambda_{1} \ldots \lambda_{t}-\pi_{0}}{\lambda_{1} \ldots \lambda_{t-1}-\pi_{0}}=\frac{\Pi_{s=1}^{t} B^{-1}\left(\varphi^{-1}\left(\delta_{G}^{T+1-s} \varphi(1)\right)\right)-\pi_{0}}{\prod_{s=1}^{t-1} B^{-1}\left(\varphi^{-1}\left(\delta_{G}^{T+1-s} \varphi(1)\right)\right)-\pi_{0}}, \\
& \forall t>1 \text { and } \mu_{1}=\frac{\lambda_{1}-\pi_{0}}{1-\pi_{0}},
\end{aligned}
$$

while the equilibrium probability that the government is benevolent is

$$
\pi_{t-1}=\frac{\pi_{0}}{\lambda_{1} \ldots \lambda_{t-1}}=\frac{\pi_{0}}{\Pi_{s=1}^{t-1} B^{-1}\left(\varphi^{-1}\left(\delta_{G}^{T+1-s} \varphi(1)\right)\right)}, \quad \forall t>1 .
$$

Our analysis is based on the assumption that the benevolent government never wants to predate. This is just for the sake of simplicity. In section 4, we extend our analysis to the case where the benevolent government extracts some resources from the private sector and demonstrate that this does not qualitatively alter our results.

\subsection{The Dynamics: Equilibrium Divergence and Unstable Growth}

In equilibrium, the dynamics of the political and economic variables can be modeled as a discrete Markov chain, with $T+2$ states. The underlying state variable is the number of periods without predation, or, equivalently the updated probability that the current government is benevolent. Correspondingly, we label the states by the tenure of the non-predatory government. In state 1, it is the first period during which the government is in office, either because the game is just starting or because the previous government has been overthrown and a new one has just been drawn. Similarly, in state 2 the government currently in place was new last period and did not predate then. In state 0 , the government has already been observed to predate and has not been overthrown. More precisely,

- In state 0 , the government is known to be predatory. Accordingly no citizen dares to enter the politically vulnerable modern sector. Hence, $\beta=Y=0$.

- In state 1 , the probability that the government is benevolent is $\pi_{0}$ and the fraction of the population working in the modern sector is $\beta_{1}=B\left(\lambda_{1}\right)$.

- State $t \in\{2, \ldots, T\}$ arises after the government has been observed to show restraint during $t-1$ periods. In that case, the probability that 
the government is benevolent is $\pi_{t-1}$ and the fraction of the population working in the modern sector is $\beta_{t}=B\left(\lambda_{t}\right)$.

- State $T+1$ arises after the government has been observed to show restraint during $T$ periods. In that case, the government is known to be benevolent, and full development obtains, with $\beta_{T+1}=1$.

The analysis above, and in particular Proposition 2, yields the transition probabilities that attach to each state. Interpreting $\delta_{G}$ as the probability that there is no exogenous political shock, we obtain the following:

Once the economy reaches state 0 , it is trapped there until the government is overthrown because of an exogenous event. After such a shock (which happens with probability $1-\delta_{G}$ ), the economy moves to state 1 .

From state $t \in\{1, \ldots, T\}$, if there is an exogenous political shock, the economy enters state 1 . Otherwise, if the government shows restraint the economy moves to state $t+1$. This transition, corresponding to gradual economic development, occurs with probability $\delta_{G} \lambda_{t}$. But if the government is observed to predate, the economy collapses. If the predatory government is overthrown, the economy moves to state 1 , where it gets a fresh start. This sequence of events happens with probability $\delta_{G}\left(1-\lambda_{t}\right) v$. If the predatory government stays in power, the collapse is durable, as the economy moves to state 0 . This sequence of events happens with probability $\delta_{G}\left(1-\lambda_{t}\right)(1-v)$.

Once the economy reaches state $T+1$, full development obtains. Full development persists with probability $\delta_{G}$. If there is an exogenous political shock, which happens with probability $1-\delta_{G}$, the economy moves back to state 1 .

The dynamics of this Markov chain are illustrated in Figure 2. As the figure illustrates, the Markov chain is irreducible, i.e. starting from any of the states it is possible to get to any of the other states. It is also aperiodic. Therefore it admits a unique ergodic distribution. The transition probability matrix, which we denote by $M$, is

$$
M=\left(\begin{array}{ccccccc}
\delta_{G} & 1-\delta_{G} & 0 & 0 & . & . & 0 \\
\delta_{G}\left(1-\lambda_{1}\right)(1-v) & \left(1-\delta_{G}\right)+\delta_{G}\left(1-\lambda_{1}\right) v & \delta_{G} \lambda_{1} & 0 & . & . & 0 \\
\cdot & \cdot & . & . & . & . & . \\
\delta_{G}\left(1-\lambda_{t}\right)(1-v) & \left(1-\delta_{G}\right)+\delta_{G}\left(1-\lambda_{t}\right) v & 0 & . & \delta_{G} \lambda_{t} & . & 0 \\
\cdot & \cdot & . & . & . & \cdot & \cdot \\
\delta_{G}\left(1-\lambda_{T}\right)(1-v) & \left(1-\delta_{G}\right)+\delta_{G}\left(1-\lambda_{T}\right) v & 0 & . & . & \cdot & \delta_{G} \lambda_{T} \\
0 & 1-\delta_{G} & 0 & . & . & \cdot & \delta_{G}
\end{array}\right) .
$$

The ergodic distribution is the probability vector $P$ such that $M P=P$. It is given in the next proposition. 


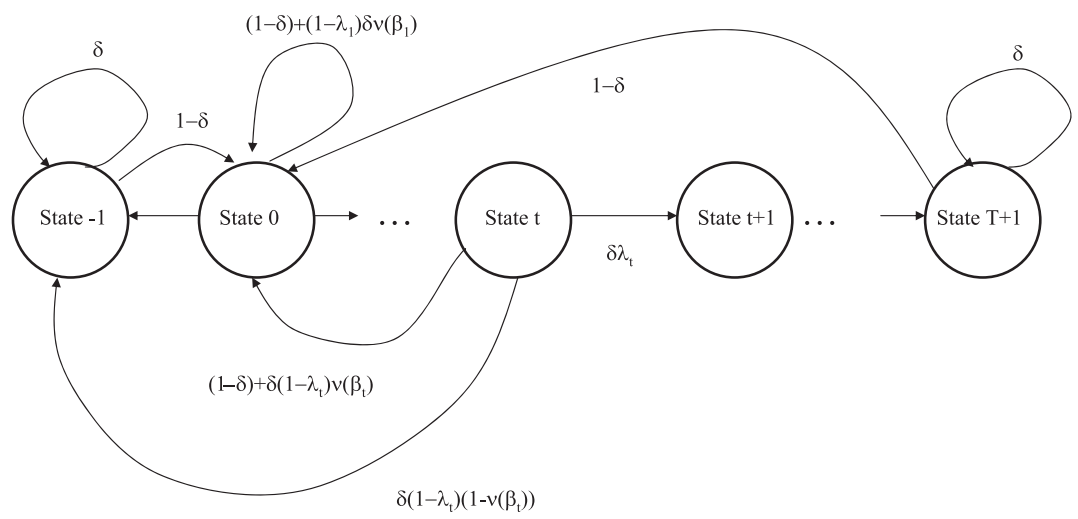

Figure 2. The Equilibrium Markov Chain.

Proposition 3. In the ergodic distribution, the $T+2$ possible states of the economy have equal weight.

The proposition implies that most of the time ( $T$ periods out of $T+2$ ), the agents in the economy are unsure about the exact type of the government. The government has not been observed to predate and thus some fraction $\beta_{t} \in\left(0, \beta^{*}\right]$ of the agents choose to operate in the modern sector. $1 /(T+2)$ of the time, however, the government is known to be predatory, and no one dares to enter the politically vulnerable sector. Also, $1 /(T+2)$ of the time, the government is known to be benevolent, and the economy has reached full development.

\section{LIMITED PREDATION}

In this section, we extend our model to address the case where both government types would like to extract resources from the citizens. The difference between the two types is one of nature rather than degree. While the predatory government would like to extract all the resources from the citizens, the more benevolent government is satisfied with a fraction $\theta$ of these resources and is willing to leave the rest to the citizens. And we retain the assumption that the traditional informal sector escapes predation.

There are now two possible equilibria: one in which the opportunistic government permanently pools with the more benevolent one, thus limiting predation to $\theta$; the other where the opportunistic government only temporarily pools with the benevolent one, eventually opting for total predation. While the former equilibrium is similar to that analyzed by Besley (1997), the latter is a variant of the equilibrium we analyzed above.

Consider the first. Citizens and firms anticipate that both types of government will permanently tax a fraction $\theta$ of $Y$. Were the opportunistic 
government to deviate from such limited predation, then all citizens would interpret this as a signal that the government is predatory and permanently revert to the traditional sector. As long as predation is limited, firm profits are sufficient to pay wages. The equilibrium condition that citizens be indifferent between the two sectors implies $w=1$. Firms choose $\beta$ to maximize $(1-\theta) Y(\beta)-\beta$. The first-order condition is $(1-\theta) Y^{\prime}(\beta)=1$ and, since $Y$ is concave, the second-order condition holds. The equilibrium proportion of citizens working in the modern sector is therefore $\hat{\beta}=Y^{\prime-1}(1-\theta)^{-1}$. Given our assumptions on $Y, \beta<1$. While, without taxation, all citizens would operate in the more productive modern sector, limited predation encourages some of them to remain in the traditional sector, which is shielded from government interference.

Now, turn to the strategy of the opportunistic government. Were it to choose permanent limited predation, its discounted utility would be

$$
\sum_{t=0}^{\infty} \delta_{G}^{t} \theta Y(\hat{\beta})=\frac{\theta Y(\hat{\beta})}{1-\delta_{G}},
$$

while if it chose instant total predation it would be $\varphi(\hat{\beta})=(1-v) Y(\hat{\beta})$. Combining the conditions obtained for the government and for the citizens yields the following proposition.

Proposition 5. There exists an equilibrium where both government types permanently exert limited predation, by taxing a fraction $\theta$ of the modern sector output, if and only if

$$
\theta \geq(1-v)\left(1-\delta_{G}\right)
$$

The proposition implies that a limited predation equilibrium is more likely to exist when the ability of the people to resist full predation $(v)$ is large. When $v$ is large, limited predation is attractive relative to full predation, since the latter creates the risk of being overthrown.

But what if condition (7) does not hold? In that case the equilibrium is similar to that analyzed in the previous section. The opportunistic government strategically mixes between restraint (with probability $\mu_{t}$ ) and predation. Along the no-predation path, citizens upgrade their expectations about the type of the government. And, if the government is opportunistic, at some point predation occurs. To use Olson's terminology, when condition (7) holds, the state is a "stationary bandit." When that condition does not hold, the opportunistic government initially mimics the "stationary bandit," but eventually turns into a "roving bandit."

For brevity we only sketch the formal analysis of the latter case: Bayesian updating by the citizens is still as in Lemma 1 and wages in the modern sector are as in section 3.2. Similarly to that section, the profit maximization condition for the modern sector firms is $Y^{\prime}\left(\beta_{t}\right)(1-\theta)=\left(\lambda_{t}+\left(1-\lambda_{t}\right) v\right)^{-1}$, which 
implicitly defines the function $\hat{B}($.$) , mapping the probability of restraint, \lambda_{t}$, into the fraction of the citizens working in the modern sector. Also, similarly to section 3.3, the Bellman equation for the opportunistic government is

$$
J_{t}=\max _{\mu_{t} \in[0,1]}\left(1-\mu_{t}\right) \varphi\left(\beta_{t}\right)+\mu_{t}\left[\theta Y\left(\beta_{t}\right)+\delta_{G} J_{t+1}\right] .
$$

Thus, along the no-predation path, we have the following indifference condition: $(1-v-\theta) Y\left(\beta_{t}\right)=\delta_{G} J_{t+1}$. As in the above section, one can then characterize the endogenous horizon of this game, recursively compute the value function of the government and close the equilibrium by solving for the sequence of updated probabilities.

\section{IMPLICATIONS}

This section brings our theoretical analysis to bear upon stylized facts and suggests implications for empirical testing.

As noted in Pritchett (2000), some countries have a steady growth path resembling "hills." In other countries, initial growth is followed by economic decline, a path resembling "mountains." In our model, "hills" arise in equilibrium when there is no predation and moderate but steady growth occurs. "Mountains" arise when the government eventually predates and growth collapses. Thus our model offers a theoretical rationale as well as additional qualifications for the pattern observed by Pritchett (2000).

Implication 1. The decline in growth rate associated with "mountains" should occur around the time of political predation and be large. The positive growth rates observed in the case of "hills" should be relatively smaller and follow political restraint.

Consider, for example, the case of Zimbabwe. Despite having endorsed socialist doctrines and overthrown the government of the prosperous European minority, so long as Mugabe ruled with restraint, Zimbabwe's economy grew. But when in 2002 Mugabe's supporters began to invade commercial farms and his colleagues to seize commercial and financial institutions, expectations radically altered. Investment ceased, capital and labor fled the formal economy, and Zimbabwe's once prosperous economy collapsed.

If Zimbabwe offers an example of a "mountain," Botswana stands as one of Pritchett's hills. At the time of independence, Botswana was poor; with a semi-arid economy and no known mineral wealth, the export of meat and hides underpinned its economy. While the subsequent discovery of diamond deposits offered the opportunity for growth, it also offered opportunity for predation. The deposits were located within the home district of the president, Seretse Khama, but he insisted that rights to the resources be vested in the nation. In addition, he recruited an economic team that devised policies aimed at maximizing the intertemporal flow of revenues from the 
deposits rather than their immediate consumption. Repeatedly signaling its role as a custodian of the wealth of the nation, Khama behaved with restraint. Our analysis implies that such restraint should have resulted in the expansion of the economy, and the data are consistent with such an implication.

As stated by Lucas $(1988$, p. 4), "within the advanced countries growth rates tend to be stable over long periods of time" while among developing countries "there are many examples of sudden, large changes in growth rates." Our model offers insights into these stylized facts as well. ${ }^{11}$

Consider the random variable taking the value 1 when predation occurs (which happens with probability $1-\lambda_{t}$ ) and 0 otherwise. Its variance, $\sigma_{t}^{2}=\lambda_{t}\left(1-\lambda_{t}\right)$, is a measure of risk in our model. In the early stages of development, as the economy grows, both $\lambda_{t}$ and $\sigma_{t}^{2}$ increase on the nopredation path. Once $\lambda_{t}>\frac{1}{2}$, which corresponds to a more mature economy, growth occurs while risk declines. This discussion leads to the following testable implication of our theoretical analysis.

Implication 2. The evolution of political risk during the development path should be humpshaped. Our model predicts that, other things equal, political risk should be limited in poor stagnating economies, larger in developing economies, and low in developed economies.

Political risk premia: When political risk is large, employees must be promised a relatively high wage in the case where the government does not predate and governments must promise high yields on their bonds. This leads to our next implication.

Implication 3. Political risk generates a wedge between the wages promised in the modern sector and the traditional or informal sector and also increases the promised yield on government bonds. The greater the risk of predation, the larger these premia. The longer the period without predation, the lower these premia.

Q4 Starting with Simon Kuznets (1966), scholars have argued that inequality increases at initial stages of growth and then subsequently declines. This pattern is also implied by the logic of the model. To quantify income inequality in our model, consider the Lorenz curve plotting the cumulative percentage of income against the cumulative percentage of population. The Gini coefficient is the area between the first diagonal and the Lorenz curve. In our model, this is

$$
G=\frac{1}{2} \frac{(1-\beta) \beta(w-1)}{1+\beta(w-1)},
$$

\footnotetext{
${ }^{11}$ Acemoglu and Zilibotti (1997) offer an interesting alternative approach, where early-stage economies are more risky because they are less diversified.
} 
a function that is first increasing, and then decreasing in $\beta$. Hence, along the no-predation path, the Gini coefficient increases and then decreases, conforming to the logic of the Kuznets' curve. Initially all workers operate in the traditional sector and there is no inequality. Then, as long as the government does not predate, workers progressively move to the modern sector where they earn larger wages. This induces an increase in inequality. If the government does not predate, the majority of the population eventually moves to the modern sector and inequality decreases. And if the government predates, the population reverts to the traditional sector, where inequality is low.

In a country with little political risk and an initially reputable government, the initial rise in inequality should be limited and income inequality quickly diminishes. With large predation risk, the initial increase in inequality is stronger, since the political premium in wages is greater, and it takes longer for a reduction in inequality to obtain. Thus, our model yields the following empirical implication.

Implication 4. Countries with greater initial political risk should have more humped Kuznets' curves.

The ability to extract a fraction of the output via taxation reduces the temptation for opportunistic governments to engage in full predation. In practice, it is difficult for governments to extract resources from the private sector and $\theta$ is constrained to be small when taxation institutions are weak, which is typical or poor countries. This leads to our next implication.

Implication 5. Weak taxation institutions enhance political risk.

In addition to the inefficiency of the fiscal system, international pressure can constrain the ability of relatively benevolent governments to extract resources from the private sector. Developed nations can curb aid or raise tariffs when governments do not follow internationally approved "best practices." In our model this leads to a decrease in $\theta$. Of course, rich and powerful countries can also inflict punishments when governments exert full predation, which, in our model, increases $v$.

The late 20th century offers an interesting example. During the cold war, the ability of the developed democracies to punish misbehaving rulers in the South was limited by need for allies in the struggle against communism. With the fall of the Soviet Union, Western democracies had less need for allies and were therefore more willing to pressure governments in the developing world to limit predatory practices. Based on our reasoning, the resultant decrease in $\theta$ would be politically destabilizing. The surge in political instability associated with the end of the cold war is consistent with this implication of our model, which we state below. 
Implication 6. International pressure to curb limited government predation can increase political risk and jeopardize growth.

What of governments who have spoiled their reputations? Are their nations fated to remain poor? Our model offers the following, rather pessimistic implication:

Implication 7. When they engage in full predation, governments ruin their reputation and are afterwards unable to recover them. In such cases, growth will return only after major political changes, as when new regimes assume power.

This implication of our theoretical analysis is consistent with the findings of Haggard and Webb (1994) and Jones and Olken (2004).

\section{CONCLUSION}

Development, we have argued, involves the joint evolution of economic growth and political expectations. The political and economic histories that arise in the course of development are unstable. Predation and collapse can follow growth, and be themselves followed by economic rebound. The major driver of growth in this process is political restraint.

Only liberal regimes that respect property rights and do not capriciously alter the rules of the game to their own advantage can achieve development. But our emphasis on the role of political leaders and the formation of political expectations leads us away from the study of formal institutions and to an appreciation of the impact of political history and culture. Indeed, our Q5 investigation cautions against the prescription of "best practice." For we have shown that to the extent that institutions prevent limited predation, they may in fact encourage full-scale predation, should leaders be opportunistic. In addition, we have demonstrated that, even while commendable on their face, formal institutions may not be effective in practice. Institutions that perform well in North America can fail to achieve similar outcomes in countries with different histories and expectations (see the case of Latin America, studied by Engerman and Sokoloff, 1997, and Engerman et al., 2000). We are thus driven to a less "rule governed" vision of the role of politics in economic development.

\section{APPENDIX A: PROOFS}

Proof of Lemma 2. $\beta_{t}$ is chosen to maximize $\left(\lambda_{t}+\left(1-\lambda_{t}\right) v\right) Y\left(\beta_{t}\right)-\beta_{t}$. When $\lambda_{t}=1$, the optimum is $\beta_{t}=1$ and when $\lambda_{t}=0$ it is $\beta_{t}=0$. Turning to interior values of $\lambda_{t}$ first note that the derivative of the objective function with respect to $\beta_{t}$ is $\left(\lambda_{t}+\left(1-\lambda_{t}\right) v\right) Y^{\prime}\left(\beta_{t}\right)-1$. The second-order condition holds since the production function is concave. The constraints $\beta_{t} \leq 1$ and 
$\beta_{t} \geq 0$ are not binding. Hence, the optimum is pinned down by the firstorder condition, i.e.

$$
Y^{\prime}\left(\beta_{t}\right)=\frac{1}{\lambda_{t}+\left(1-\lambda_{t}\right) v} .
$$

The right-hand side of (A1) is decreasing in $\lambda_{t}$, while its left-hand side is independent of $\lambda_{t}$. Hence, an increase in $\lambda_{t}$ implies an increase in the value of $\beta_{t}$ for which the two curves intersect.

Proof of Proposition 1. By definition, when $\pi_{t-1}$ reaches $\pi^{*}$ a fraction $\beta^{*}$ of the citizens enter the formal sector. Since they anticipate that the opportunistic government always predates at this point in time, after observing no predation at time $t$, the citizens rationally update $\pi_{t}$ to 1 . Hence, if the opportunistic government waits another period before predating, his expected utility is $\delta_{G} \varphi(1)$. Consequently, by construction of $\beta^{*}$, predating now is optimal for the opportunistic government.

Proof of Proposition 2. The proof proceeds in three steps:

First step: Relying on Lemma 1, (1), and Bayes' law, we obtain $\mu_{t}$ and $\pi_{t-1}$ as a function of $\lambda_{t}$. The probability of restraint at time 1 is $\lambda_{1}=\pi_{0}+$ $\left(1-\pi_{0}\right) \mu_{1}$. This implies that $\mu_{1}=\left(\lambda_{1}-\pi_{0}\right)\left(1-\pi_{0}\right)^{-1}$. The proof proceeds by induction.

To prove that the property holds at time 2 , we must prove that $\mu_{2}=$ $\left(\lambda_{1} \lambda_{2}-\pi_{0}\right) /\left(\lambda_{1}-\pi_{0}\right)$. The probability of restraint at time 2 is $\lambda_{2}=\pi_{1}+$ $\left(1-\pi_{1}\right) \mu_{2}$. Thus, $\mu_{2}=\left(\lambda_{2}-\pi_{1}\right)\left(1-\pi_{1}\right)^{-1}$. From Lemma $1, \pi_{1}=\pi_{0}\left(\pi_{0}+\right.$ $\left.\left(1-\pi_{0}\right) \mu_{1}\right)^{-1}$. Hence,

$$
\mu_{2}=\frac{\lambda_{2}\left[\pi_{0}+\left(1-\pi_{0}\right) \mu_{1}\right]-\pi_{0}}{\left(1-\pi_{0}\right) \mu_{1}} .
$$

Substituting $\quad \lambda_{1}=\pi_{0}+\left(1-\pi_{0}\right) \mu_{1} \quad$ and $\quad\left(1-\pi_{0}\right) \mu_{1}=\lambda_{1}-\pi_{0}, \quad \mu_{2}=$ $\left(\lambda_{2} \lambda_{1}-\pi_{0}\right)\left(\lambda_{1}-\pi_{0}\right)^{-1}$, completes the first step of the proof. Next we need to prove that if the property holds until time $t-1$, then it also holds at time $t$. By definition of $\lambda_{t}, \mu_{t}\left(\lambda_{t}-\pi_{t-1}\right)\left(1-\pi_{t-1}\right)^{-1}$. From Lemma 1 ,

$$
1-\pi_{t-1}=\frac{\left(1-\pi_{0}\right) \mu_{1} \ldots \mu_{t}}{\pi_{0}+\left(1-\pi_{0}\right) \mu_{1} \ldots \mu_{t}} .
$$

Substituting in $\mu_{t}$,

$$
\mu_{t}=\frac{\lambda_{t}\left[\pi_{0}+\left(1-\pi_{0}\right) \mu_{1} \ldots \mu_{t-1}\right]-\pi_{0}}{\left(1-\pi_{0}\right) \mu_{1} \ldots \mu_{t-1}} .
$$


That the property holds for all time $\tau<t$ implies that

$$
\begin{aligned}
\mu_{1} \ldots \mu_{t-1} & =\frac{\lambda_{1}-\pi_{0}}{1-\pi_{0}} \frac{\lambda_{1} \lambda_{2}-\pi_{0}}{\lambda_{1}-\pi_{0}} \cdots \frac{\left(\lambda_{1} \ldots \lambda_{t-1}\right)-\pi_{0}}{\left(\lambda_{1} \ldots \lambda_{t-2}\right)-\pi_{0}} \\
& =\frac{\left(\lambda_{1} \ldots \lambda_{t-1}\right)-\pi_{0}}{1-\pi_{0}} .
\end{aligned}
$$

Substituting $\mu_{1} \ldots \mu_{t-1}$ into $\mu_{t}$, the result obtains. Finally turn to the analysis of $\pi_{t-1}$. As shown above in this proof,

$$
\mu_{1} \ldots \mu_{t-1}=\frac{\left(\lambda_{1} \ldots \lambda_{t-1}\right)-\pi_{0}}{1-\pi_{0}} .
$$

Substituting $\mu_{1} \ldots \mu_{t-1}$ in $\pi_{t-1}$, we get $\pi_{t-1}=\pi_{0} /\left(\lambda_{1} \ldots \lambda_{t-1}\right)$.

Second step: Relying on the first step we prove that there exists a time $T$ at which $\pi_{t-1}$ reaches $\pi^{*}$. Since, is increasing in $t$,

$$
\pi_{t-1}=\frac{\pi_{0}}{\lambda_{1} \ldots \lambda_{t-1}}>\frac{\pi_{0}}{\left(\lambda_{t-1}\right)^{t-1}}>\frac{\pi_{0}}{\left(\lambda_{T}\right)^{t-1}}=\frac{\pi_{0}}{\left(\pi^{*}\right)^{t-1}} .
$$

Since $\pi^{*}$ is a constant lower than 1 , as $t$ goes to infinity, $\pi_{0} /\left(\left(\pi^{*}\right)^{t-1}\right)$ grows unboundedly. Hence, there exists a value of $t$ such that $\pi_{t-1}$ reaches $\pi^{*}$.

Third step: Combining Lemma 4, which gives $\lambda_{t}$ as a function of the exogenous parameters, and the previous step of the proof, which gives $\mu_{t}$ and $\pi_{t-1}$ as functions of $\lambda_{t}$, we obtain the strategy of the opportunistic government and the beliefs of the citizens. Substituting in the value of $\beta_{t}$ from Lemma 3, we obtain the value of $\lambda_{t}$ stated in the proposition. Substituting $\pi_{t-1}=\pi_{0} /\left(\lambda_{1} \ldots \lambda_{t-1}\right)$ in the value of $\lambda_{t}$ given above, we obtain

$$
\pi_{t-1}=\frac{\pi_{0}}{\lambda_{1} \ldots \lambda_{t-1}}=\frac{\pi_{0}}{\Pi_{s=1}^{t-1} B^{-1}\left(\varphi^{-1}\left(\delta_{G}^{T+1-t} \varphi(1)\right)\right)} .
$$

Finally, substituting the value of $\lambda_{t}$ into the value of $\mu_{t}$ given above, we obtain

$$
\mu_{t}=\frac{\left(\lambda_{1} \ldots \lambda_{t}\right)-\pi_{0}}{\left(\lambda_{1} \ldots \lambda_{t-1}\right)-\pi_{0}}=\frac{\Pi_{s=1}^{t} B^{-1}\left(\varphi^{-1}\left(\delta_{G}^{T+1-t} \varphi(1)\right)\right)-\pi_{0}}{\prod_{s=1}^{t-1} B^{-1}\left(\varphi^{-1}\left(\delta_{G}^{T+1-t} \varphi(1)\right)\right)-\pi_{0}} .
$$

Proof of Proposition 3. The column vector $P$ has $T+2$ elements, denoted by $p_{i}, i \in\{0,1, \ldots T+1\}$. Multiplying the first row of $M$ by $P$, we obtain $p_{0} \delta_{G}+p_{1}\left(1-\delta_{G}\right)$, which simplifies to $p_{0}=p_{1}$. Multiplying the second row of $M$ by $P$, we obtain

$$
p_{0} \delta_{G}\left(1-\lambda_{1}\right)(1-v)+p_{1}\left(\left(1-\delta_{G}\right)+\delta_{G}\left(1-\lambda_{1}\right) v\right)+p_{2} \delta_{G} \lambda_{1}=p_{2} .
$$

Substituting $p_{0}=p_{1}$ and simplifying, we obtain $p_{0}=p_{2}$. Iterating, we find that all the elements of $P$ are equal. 


\section{ACKNOWLEDGMENTS}

Many thanks for insightful comments to the editor, Enrico Spolaore, and two anonymous referees, as well as to Daron Acemoglu, Macartan Humphreys, Simon Johnson, Thomas Mariotti, Fabrizio Zilibotti, and participants at the seminar of the Center for the Study of African Economies, Oxford University, the IIES, Stockholm University, the Conference on Endogenous Institutional Change, Stanford University, and the NYU Economics Lunch Seminar.

JEAN PAUL AZAM
Toulouse School of Economics

ROBERT BATES

BRUNO BIAIS

Toulouse School of Economics

\section{REFERENCES}

Acemoglu, D. and S. Johnson, 2004, Unbundling institutions. Working paper, MIT. , and J. A. Robinson, 2001, The colonial origins of comparative development: an empirical investigation. American Economic Review 91, 1369-1401. making of the modern world income distribution. Quarterly Journal of Economics 117, 1231-1294.

cation and growth. Journal of Political Economy 105, 709-751.

Alesina, A. and G. Tabellini, 1989, External debt, capital flight and political risk. Journal of International Economics 27, 199-220.

Bates, R. H., 1981, Markets and States in Tropical Africa (University of California Press, California, CA).

Besley, T., 1997, Monopsony and time-consistency: sustainable pricing policies for perennial crops. Review of Development Economics 1, 57-70.

Easterly, W., M. Krener, L. Pritchett, and L. Summers, 1993, Good policy or good luck? Country growth performance and temporary shocks. Journal of Monetary Economics 32, 459-483.

Engerman, S., S. Haber, and K. Sokoloff, 2000, Inequality, institutions, and differential paths of development among New World economies, in: C. Menard, ed., Institutions, Contracts and Organizations (Edward Elgar, Cheltenham, UK).

— and K. Sokoloff, 1997, Factor endowments, institutions, and different paths of development among New World economies, in: S. Haber, ed., How Latin America fell behind (Stanford University Press, Palo Alto, CA).

Glaeser, E., R. La Porta, F. Lopez de Silanes, and A. Shleifer, 2004, Do institutions cause growth? Journal of Economic Growth 9, 271-303.

Haggard, S., and S. B. Webb, eds., 1994, Voting for Reform (Oxford University Press for the World Bank, New York).

Harris, J. and M. Todaro, 1970, Migration, unemployment, and development: a twosector analysis. American Economic Review 40, 126-142. 
Hausmann, R., F. Rodriguez et al., 2006, Growth Collapses (Center for International Development, Harvard University, Cambridge, MA).

Hicks, J., 1969, Theory of Economic History (Oxford University Press, Oxford).

Jerzmanowski, M., 2006, Empirics of hills, plateaus, mountains, and plains: A Markov-switching approach to growth. Journal of Development Economics 81, 357-385.

\section{Q11}

Jones, B. and B. Olken, 2004, Do leaders matter? National leadership and growth since World War II. Working Paper, Northwestern University.

Kreps, D. and R. Wilson, 1982, Reputation and imperfect information. Journal of Economic Theory 27, 253-279.

Lal, D., 1983, The Poverty of Development Economics (The Institute of Economic Affairs, London).

Lewis, A., 1954, Economic development with unlimited supplies of labor. Manchester School of Economic and Social Studies 22, 139-191.

Lucas, R., 1988, On the mechanics of economic development. Journal of Monetary Economics 22, 3-42.

Maddison, A., 2001, The World Economy: A Millenial Perspective (Development Center of the OECD, Paris).

Maskin, E. and J. Tirole, 2001, Markov perfect equilibrium, I: observable actions. Journal of Economic Theory 100, 191-219.

Milgrom, P. and K. Roberts, 1982, Predation, reputation and entry deterrence. Journal of Economic Theory 27, 280-312.

Murphy, M., A. Shleifer, and R. Vishny, 1989a, Industrialization and the big push. Journal of Political Economy 97, 1003-1026.

- - - - and — 1989b, Income distribution, market size and industrialization. Quarterly Journal of Economics 104, 537-564.

North, D. C. and B. R. Weingast, 1989, Constitutions and commitment: the evolutions of institutions governing public choice in seventeenth-century England. Journal of Economic History 69, 803-832.

Perotti, E., 1995, Credible privatization. American Economic Review 85, 847-859.

Phelan, C., 2004, Public trust and government betrayal. Journal of Economic Theory 127, 27-43.

Q12 Pritchett, L., 1995, Divergence, big time. Journal of Economic Perspectives 11, 3-17.

- 2000, Understanding patterns of economic growth. World Bank Economic Review 14, 221-250.

Rodrik, D., 1989, Promises, promises: Credible policy reform via signalling. Economic Journal 99, 756-772.

—_ 1991, Policy uncertainty and private investment in developing countries. Journal of Development Economics 36, 229-243.

- 1999 , Where did all the growth go? External shocks, social conflict, and growth collapses. Journal of International Economics 40, 1-22.

Root, H., 1989, Tying the King's hands: credible commitments and royal fiscal policy during the old regime. Rationality and Society 1, 240-258.

Rosenstein-Rodan, P., 1943, Problems of industrialization in Eastern and SouthEastern Europe. Economic Journal 53, 202-211.

de Soto, H., 1989, The Other Path (Harper \& Row, New York).

Weingast, B., 1995, The economic role of political institutions. Journal of Law, Economics, and Organization 7, 1-31. 


\section{Author Query Form}

\section{Journal ECPO}

Article $\quad 345$

Dear Author,

During the copy-editing of your paper, the following queries arose. Please respond to these by marking up your proofs with the necessary changes/additions. Please write your answers clearly on the query sheet if there is insufficient space on the page proofs. If returning the proof by fax do not write too close to the paper's edge. Please remember that illegible mark-ups may delay publication.

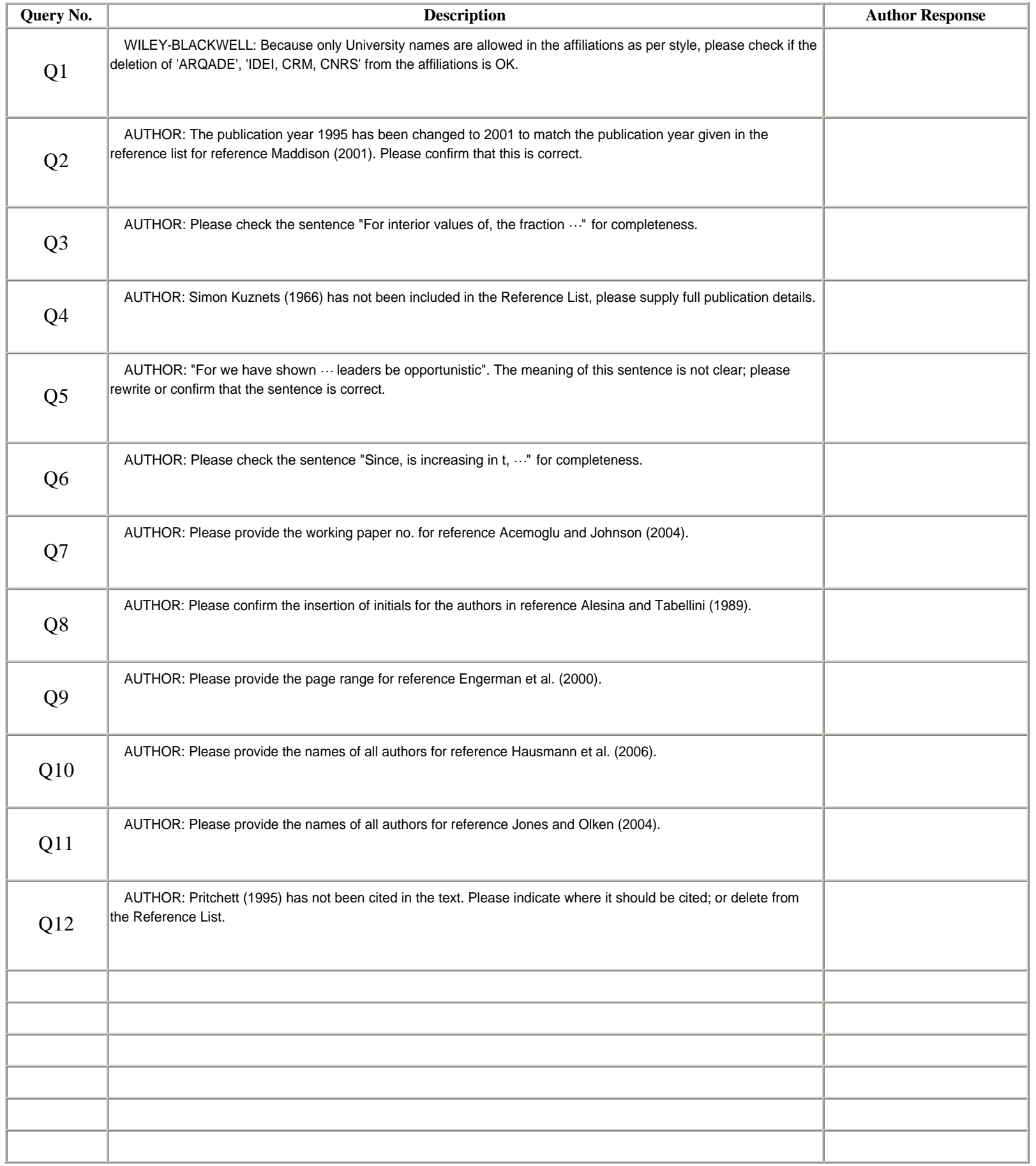

